\title{
Development of Design Charts Considering the Effect of Backfill Inclination and Wall Inclination on the Seismic Active Pressure for $c-\phi$ Soil
}

\author{
Ashish Gupta* \\ Department of Civil Engineering \\ Indian Institute of Technology Roorkee \\ Roorkee, Pin Code- 247667, Uttarakhand, India \\ *Corresponding author: shi_g2000@rediffmail.com, shi_g1982@yahoo.co.in \\ Vikas Yadav \\ Department of Civil Engineering \\ Kamla Nehru Institute of Technology (KNIT), Sultanpur \\ Sultanpur, Pin Code- 228001, India \\ Vishwas A. Sawant \\ Department of Civil Engineering \\ Indian Institute of Technology Roorkee \\ Roorkee, Pin Code- 247667, Uttarakhand, India \\ Ruchin Agarwal \\ Department of Civil Engineering \\ Kamla Nehru Institute of Technology (KNIT) Sultanpur \\ Sultanpur, Pin Code- 228001, India \\ (Received September 24, 2018; Accepted December 31, 2018)
}

\begin{abstract}
In this paper, the design charts have been presented to calculate the seismic active pressure for $c-\phi$ soil with surcharge. For developing the design charts, the explicit generalised equation based on pseudo-static approach is used. In the present study, the design charts have been presented for positive and negative wall inclination considering the inclined backfill. The effect of backfill inclination along with the effect of positive and negative wall inclination on the seismic active pressure has been noticed in the design charts. The design charts are very easy to use for the field.
\end{abstract}

Keywords- Inclined retaining wall, Pseudo-static approach, Cohesion, Surcharge, Dynamic active thrust.

\section{Introduction}

The design of retaining structures mainly depends on the lateral earth pressure exerted by the backfill material on the wall. Under normal conditions, almost all retaining structures are designed for active thrust from the retained backfills. The estimation of dynamic active thrust on the retaining walls is calculated by explicit generalized expression, in the field. This method is based on the pseudo-static approach. For cohesionless backfills, Okabe (1924), Mononobe and Matsuo (1929) reported this method in their study and then known as Mononobe and Okabe method Kramer (1996). But in real field condition, it doesn't work because of cohesion is present in the soil. For cohesive $(c-\phi)$ soil with soil cohesion, $c$, and angle of internal friction of soil, $\phi$, Shukla et al. (2009) gives a simple expression for estimating the seismic active earth pressure. But in this study wall friction and adhesion between wall face and backfill was ignored and the 
International Journal of Mathematical, Engineering and Management Sciences

Vol. 4, No. 2, 409-419, 2019

https://dx.doi.org/10.33889/IJMEMS.2019.4.2-033

wall is also assumed as vertical. Kim et al. (2010) obtained an expression for estimation of the total seismic active pressure in terms of the inclination of failure plane, but the calculation of failure plane was based on the trial and error procedure. This study has very limited applications in real design practices due to trail-error procedure. Shukla and Bathurst (2012) had included the effect of wall friction for calculating seismic active pressure on retaining wall. Shukla (2013) gave an expression to calculate seismic active pressure for sloping backfills. Shukla (2015) developed a generalized analytical expression for the dynamic active pressure on retaining wall which supports an inclined backfill of cohesive soil. The influence of many factors such as effect of wall geometry such as wall inclination and backfill inclination, cohesive/non-cohesive backfill, wall-backfill interface, tension cracks, surcharge, horizontal and the vertical ground acceleration was also examined. Using this generalized expression, for the calculation of seismic active thrust, Gupta et al. (2019) developed the design charts, showing the effect of surcharge loading. The formulation of the critical value of inclination from the horizontal of the failure plane was also developed in this study. In the present study the design charts have been presented considering the effect of soil backfill inclination along with the negative and positive wall inclination on seismic active pressure. To draw the design charts, for the calculation of seismic active pressure from $c-\phi$ soil backfill, the explicit generalised expression proposed by Shukla (2015) is used. The design charts reduce the calculation work and makes work effective under seismic condition.

\section{Analytical Derivation}

Considering the inclined retaining wall same as taken by Gupta et al. (2019) with height, $H$ supporting a cohesive soil backfill with soil cohesion $(c)$ and angle of internal friction of soil $(\phi)$ with an active trial failure wedge $\left(\mathrm{A}_{1} \mathrm{~A}_{2} \mathrm{~A}_{3}\right)$ of weight $W$. The back-face of rigid retaining wall $\left(\mathrm{A}_{1} \mathrm{~A}_{2}\right)$ is inclined at an angle $\beta$ with the horizontal. $\mathrm{A}_{2} \mathrm{~A}_{3}$ is the assumed failure plane and it passes through the bottom of the wall and makes an angle $\alpha$ with the horizontal. Horizontal and vertical seismic inertial forces are considered as $k_{\mathrm{h}} W$ and $k_{\mathrm{v}} W$, where $k_{\mathrm{h}}$ and $k_{\mathrm{v}}$ are the horizontal and the vertical seismic coefficients. A surcharge $q$ per unit surface area is considered at the top of the sloping backfill with slope angle $i$ with horizontal. $k_{\mathrm{h}} q B$ and $k_{\mathrm{v}} q B$ are surcharge loads along the horizontal and vertical planes and $B$ is the length of sloping backfill $A_{1} A_{3}$. $z_{c}$ is the depth of tension crack from the surface of the backfill. For simplification, wall height is divided as a sum of $z$ and h. The force $F$ is the resultant of frictional force $T$ and normal force $N$ and it acts on the failure plane $\mathrm{A}_{2} \mathrm{~A}_{3}$. $C_{\mathrm{a}}$ is the total adhesive force mobilized along the wall-backfill interface at an angle $\delta$ and $C$ is total cohesive force.

Now, taking equilibrium of forces in horizontal and vertical direction respectively,

$$
\begin{aligned}
& P_{a e} \cos (\beta+\delta)+\left(1 \pm k_{v}\right)(W+q B)-F \cos (\alpha-\phi)-\frac{\bar{c} H \sin (\beta-i) \sin \alpha}{\sin \beta \sin (\alpha-i)} a_{f} \bar{c} H=0 \\
& P_{a e} \sin (\beta+\delta)-k_{h}(W+q B)-F \sin (\alpha-\phi)+\frac{\bar{c} H \sin (\beta-i) \cos \alpha}{\sin \beta \sin (\alpha-i)} a_{f} \bar{c} H \cot \beta=0
\end{aligned}
$$

Eliminating $F$ from equations (1) and (2) and further simplifying, $P_{\text {ae }}$ can be expressed as: 
International Journal of Mathematical, Engineering and Management Sciences

Vol. 4, No. 2, 409-419, 2019

https://dx.doi.org/10.33889/IJMEMS.2019.4.2-033

$$
P_{a e}=\frac{1}{2}\left(\frac{a_{1} \tan ^{2} \alpha-b_{1} \tan \alpha+c_{1}}{a_{2} \tan ^{2} \alpha-b_{2} \tan \alpha+c_{2}}\right) \gamma H^{2}
$$

here,

$\theta=\tan ^{-1}\left(\frac{k_{h}}{1 \pm k_{v}}\right)$

$m_{1}=\left(\frac{1 \pm k_{v}}{\cos \theta}\right)\left[\frac{2 q}{\gamma H}+\frac{\sin (\beta-i)}{\sin \beta}\right] \operatorname{cosec} \beta$

$m_{2}=a_{f}\left(\frac{2 c}{\gamma H}\right)\left(1-\frac{z_{c}}{2 H}\right) \operatorname{cosec} \beta$

$m_{3}=\left(\frac{2 c}{\gamma H}\right)\left(1-\frac{z_{c}}{2 H}\right) \sin (\beta-i) \cos \phi \operatorname{cosec} \beta$

$a_{1}=m_{1} \cos \beta \cos (\theta-\phi)+m_{2} \cos i \sin (\beta+\phi)+m_{3}$

$b_{1}=m_{1} \sin (\beta-\theta+\phi)+m_{2} \cos (i+\beta+\phi)$

$c_{1}=m_{3}-m_{1} \sin \beta \sin (\phi-\theta)-m_{2} \sin i \cos (\beta+\phi)$

$a_{2}=\cos i \cos (\beta+\delta+\phi)$

$b_{2}=\sin (\beta+\delta+\phi+i)$

$c_{2}=\sin i \sin (\beta+\delta+\phi)$

$\mathrm{a}_{1}, \mathrm{~b}_{1}, \mathrm{c}_{1}$ and $\mathrm{a}_{2}, \mathrm{~b}_{2}, \mathrm{c}_{2}$ are the non-dimensional constants.

For optimising the value of dynamic active thrust $P_{\mathrm{ae}}$, the following condition should be satisfied:

$\frac{\partial P_{a e}}{\partial \alpha}=0 \quad$ or $\quad \frac{\partial P_{a e}}{\partial \tan \alpha}=0$

Or, $\left(a_{2} b_{1}-a_{1} b_{2}\right) \tan ^{2} \alpha-2\left(a_{2} c_{1}-a_{1} c_{2}\right) \tan \alpha+\left(b_{2} c_{1}-b_{1} c_{2}\right)=0$

Above equation (15) is solved for $\tan \alpha$ to get the critical value of the inclination of the failure plane, $\alpha=\alpha_{\mathrm{c}}$ as:

$$
\alpha_{c}=\tan ^{-1}\left[\frac{\left(a_{2} c_{1}-a_{1} c_{2}\right) \pm \sqrt{\left(a_{2} c_{1}-a_{1} c_{2}\right)^{2}-\left(a_{2} b_{1}-a_{1} b_{2}\right)\left(b_{2} c_{1}-b_{1} c_{2}\right)}}{\left(a_{2} b_{1}-a_{1} b_{2}\right)}\right]
$$

On substituting $\alpha=\alpha_{\mathrm{c}}$ into equation (3); 
International Journal of Mathematical, Engineering and Management Sciences

Vol. 4, No. 2, 409-419, 2019

https://dx.doi.org/10.33889/IJMEMS.2019.4.2-033

$P_{\text {ae }}$ is obtained as by Shukla (2015):

$P_{a e}=\frac{1}{2}\left(\frac{a_{1} \tan ^{2} \alpha_{c}-b_{1} \tan \alpha_{c}+c_{1}}{a_{2} \tan ^{2} \alpha_{c}-b_{2} \tan \alpha_{c}+c_{2}}\right) \gamma H^{2}$

Or, $K_{a e}=P_{a e} *=\frac{P_{a e}}{0.5 \gamma H^{2}}=\left(\frac{a_{1} \tan ^{2} \alpha_{c}-b_{1} \tan \alpha_{c}+c_{1}}{a_{2} \tan ^{2} \alpha_{c}-b_{2} \tan \alpha_{c}+c_{2}}\right) \gamma H^{2}$

where, $K_{\mathrm{ae}}$ is the coefficient of active earth pressure.

\section{Results and Discussion}

According to generalized analytical expression (Equation 18), the design charts are presented in terms of $c^{*}$ (non-dimensional cohesion) and $q^{*}$ (non-dimensional surcharge) as defined in equations (19) and (20) for the calculation of the total active thrust on retaining wall for surcharge with respect to different wall inclination taken as $-15^{\circ}, 0^{\circ}$ and $15^{\circ}$ with vertical $\left(\beta=75^{\circ}, 90^{\circ}\right.$ and $\left.105^{\circ}\right)$. The range of $k_{\mathrm{h}}$ are $0.0,0.1,0.2,0.3$ and 0.4 ; the ratio of $k_{\mathrm{v}} / k_{\mathrm{h}}$ are $0.0,0.25,0.50$ and 1.0; $c^{*}$ ranges as $0.0,0.05,0.1$ and 0.2 ; and $q^{*}$ taken as 0.2 . Vertical inertial force considers as positive for the upward direction.

$c^{*}=\frac{c}{\gamma H}$

$q^{*}=\frac{q}{\gamma H}$

\section{Effect of Wall Inclination on $K_{\mathrm{ae}}$}

Considering the horizontal backfill, the design charts obtained from the present study are shown in Figures 1(a-e), 2(a-e) and 3(a-d) for calculating the seismic active earth pressure coefficient $\left(K_{\mathrm{ae}}\right)$. The respective design charts for calculating the $K_{\mathrm{ae}}$ for $c-\phi$ soil backfill for the wall inclination as $\beta=75^{\circ}, 90^{\circ}$ and $105^{\circ}$ respectively. For all these cases, the surcharge loading is also taken as $q^{*}=0.2$. From the Figures $1(\mathrm{a}-\mathrm{e}), 2(\mathrm{a}-\mathrm{e})$ and $3(\mathrm{a}-\mathrm{d})$, it can be distinctly observed that the calculated value of $K_{\mathrm{ae}}$ reduces with increase in cohesion and angle of internal friction angle of soil.

For example; at $\beta=75^{\circ}, \phi=30^{\circ}, c^{*}=0.1$, and $q^{*}=0.2$, the value of $K_{\text {ae }}$ increase by about 84.0, $190.3,313.4$ and $474.9 \%$, when $k_{\mathrm{h}}$ value rises from 0.0 to $0.1,0.2,0.3$ and 0.4 respectively. The percentage increase in the $K_{\mathrm{ae}}$ is about 84.0, 57.7, 42.4 and 39.0\%, when $k_{\mathrm{h}}$ value increases from 0.0 to $0.1,0.1$ to $0.2,0.2$ to 0.3 and 0.3 to 0.4 respectively. It shows that the percentage increment is gradually reducing till $k_{\mathrm{h}}$ equal to 0.4 . 
International Journal of Mathematical, Engineering and Management Sciences

Vol. 4, No. 2, 409-419, 2019

https://dx.doi.org/10.33889/IJMEMS.2019.4.2-033

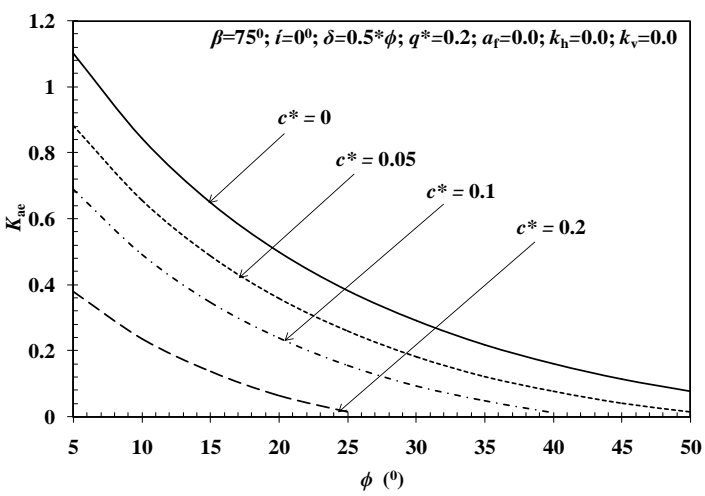

(a)

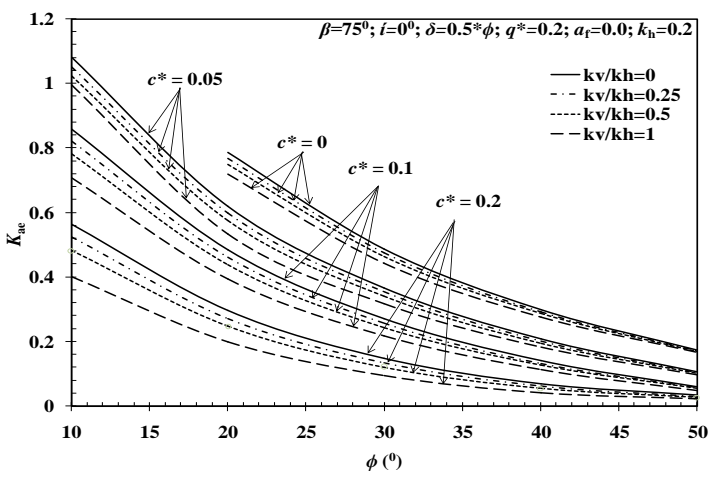

(c)

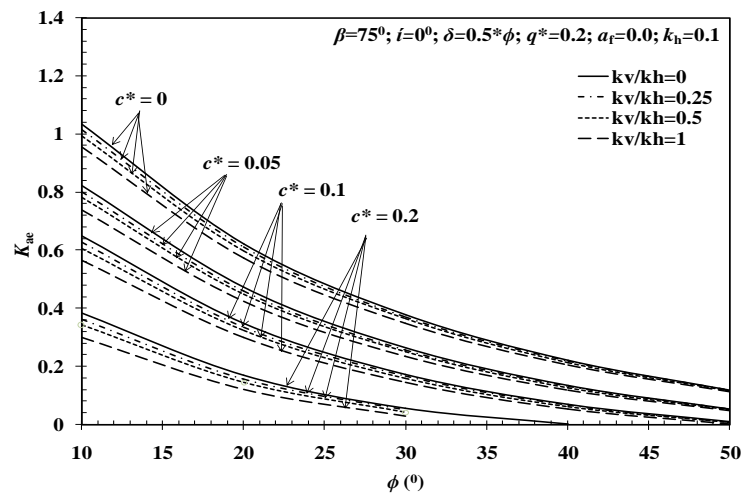

(b)

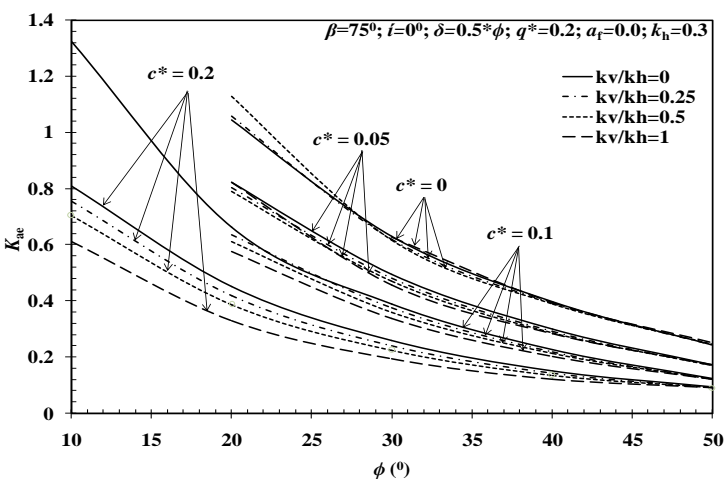

(d)

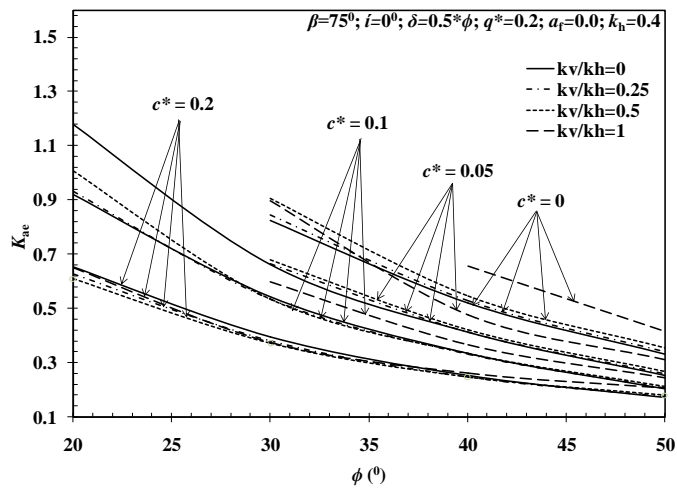

(e)

Figure 1. Design charts for $K_{\mathrm{ae}}$ for backfill slope $i=0^{\circ}$ and wall inclination $\beta=75^{\circ}$

Taking $\beta=90^{\circ}, \phi=30^{\circ}, c^{*}=0.1$, and $q^{*}=0.2$ the value of $K_{\text {ae }}$ increase by about $34.4,76.2$, 128.3 and $195.4 \%$, when $k_{\mathrm{h}}$ value rises from 0.0 to $0.1,0.2,0.3$ and 0.4 respectively. The percentage increase in the $K_{\mathrm{ae}}$ is about $34.4,31.1,29.5$ and $29.3 \%$, when $k_{\mathrm{h}}$ value increases from 0.0 to $0.1,0.1$ to $0.2,0.2$ to 0.3 and 0.3 to 0.4 respectively. It shows that the percentage increment is reducing but the rate of reduction is reducing till $k_{\mathrm{h}}$ equal to 0.4 . 
International Journal of Mathematical, Engineering and Management Sciences

Vol. 4, No. 2, 409-419, 2019

https://dx.doi.org/10.33889/IJMEMS.2019.4.2-033

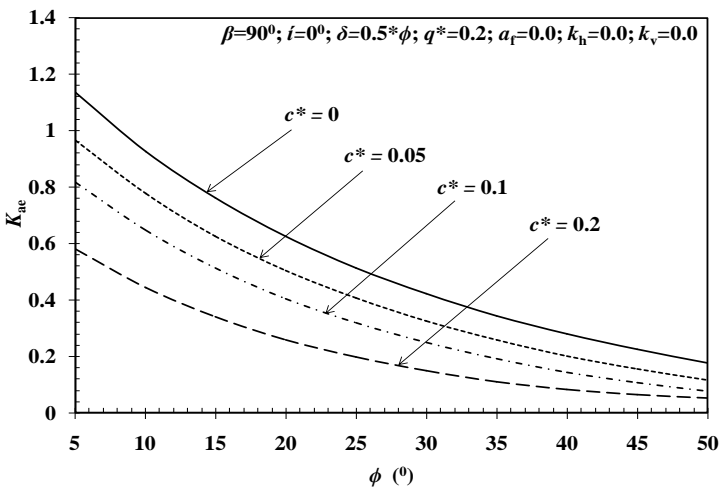

(a)

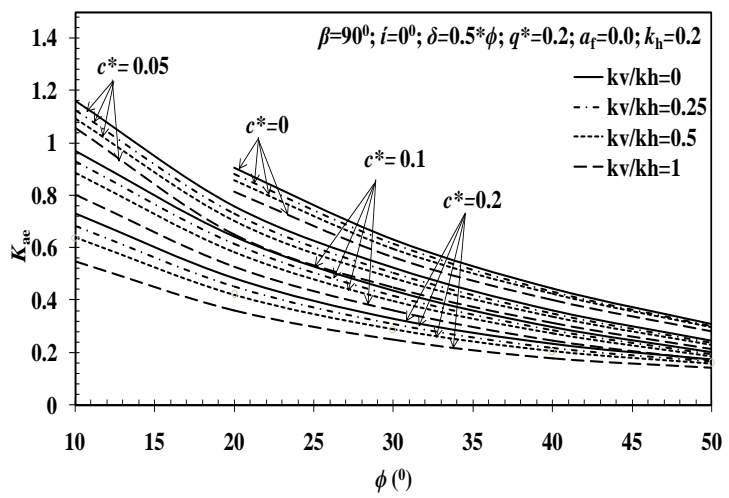

(c)

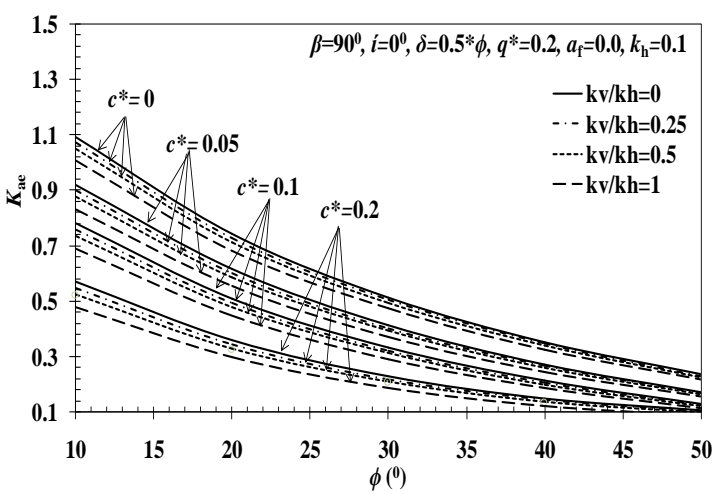

(b)

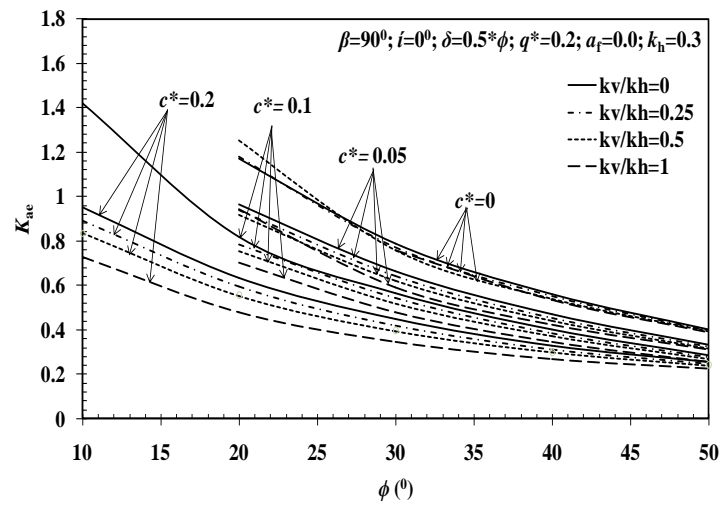

(d)

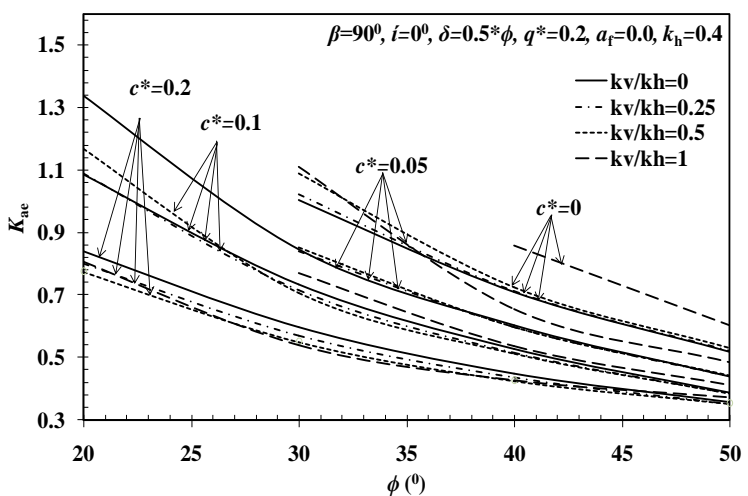

(e)

Figure 2. Design charts for $K_{\mathrm{ae}}$ for backfill slope $i=0^{\circ}$ and wall inclination $\beta=90^{\circ}$

Considering the wall inclination positive as, $\beta=105^{\circ}, \phi=30^{\circ}, c^{*}=0.1$, and $q^{*}=0.2$ the value of $K_{\mathrm{ae}}$ increase by about $22.0,49.4$ and $84.3 \%$, when $k_{\mathrm{h}}$ value rises from 0.0 to $0.1,0.2$ and 0.3 respectively. The percentage increase in the $K_{\mathrm{ae}}$ is about 22.0, 22.3 and $23.3 \%$, when $k_{\mathrm{h}}$ value increases from 0.0 to $0.1,0.1$ to 0.2 and 0.2 to 0.3 respectively. It shows that the percentage increment is also increasing for positive slope, but rate of increment is very slow with respect to $k_{\text {h. }}$. 
International Journal of Mathematical, Engineering and Management Sciences

Vol. 4, No. 2, 409-419, 2019

https://dx.doi.org/10.33889/IJMEMS.2019.4.2-033

For $\phi=30^{\circ}$ and $c^{*}=0.1$, on increasing the angle of inclination $\beta$ from $75^{\circ}$ to $90^{\circ}$ and $75^{\circ}$ to $105^{\circ}$, the value of $K_{\mathrm{ae}}$ increases about 163.1 and $359.2 \%$. Yet, the successive percentage increment is reducing with respect to increase of inclination angle.

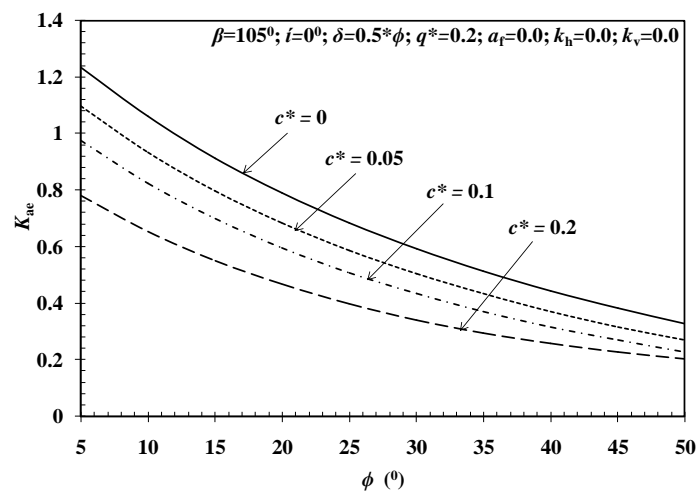

(a)

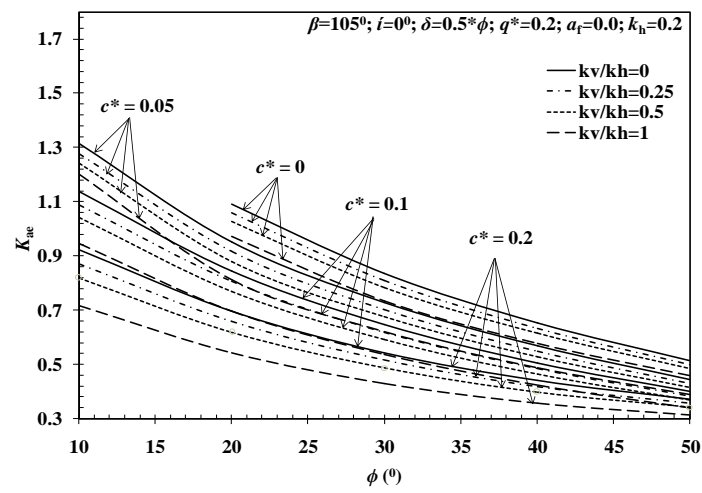

(c)

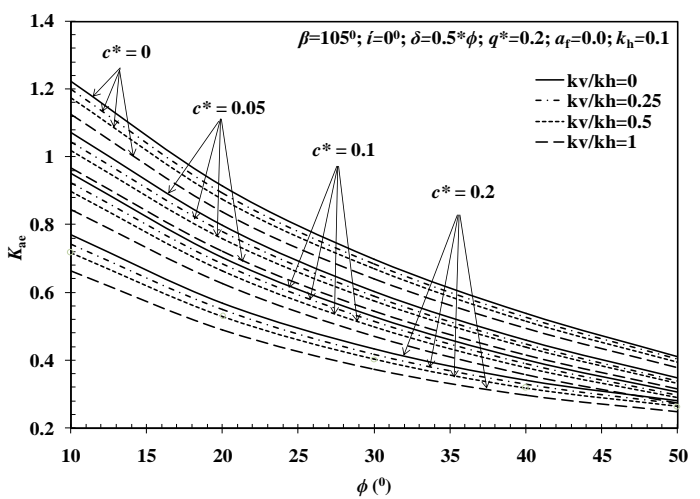

(b)

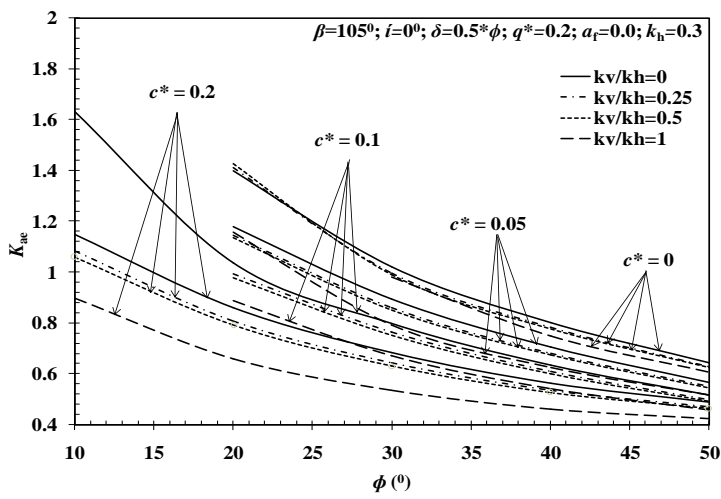

(d)

Figure 3. Design charts for $K_{\text {ae }}$ for backfill slope $i=0^{\circ}$ and wall inclination $\beta=105^{\circ}$

Effect of Wall Inclination along with the Effect of Soil Backfill Inclination on $K_{\mathrm{ae}}$

Considering the inclination of soil backfill is as $10^{\circ}$, the design charts prepared for showing the effect of backfill slope for three different wall inclination as $\left(\beta=75^{\circ}, 90^{\circ}\right.$ and $\left.105^{\circ}\right)$. In the presented charts the value of $k_{\mathrm{h}}$ ranges from 0.0 to 0.4 and four different values of $k_{\mathrm{v}}$ as $0.0,0.25$ $k_{\mathrm{h}}, 0.5 k_{\mathrm{h}}$, and $k_{\mathrm{h}}$. The vertical inertial force is considered as positive in upward direction. The design charts obtained from the present study are shown in Figures 4(a-e), 5(a-d), and 6(a-d) for the respective wall inclination. From the Figures 4(a-e), 5(a-d) and 6(a-d), it can be distinctly observed that the calculated value of the $K_{\text {ae }}$ reduces with increase in cohesion and angle of shearing resistance of soil. 
International Journal of Mathematical, Engineering and Management Sciences

Vol. 4, No. 2, 409-419, 2019

https://dx.doi.org/10.33889/IJMEMS.2019.4.2-033

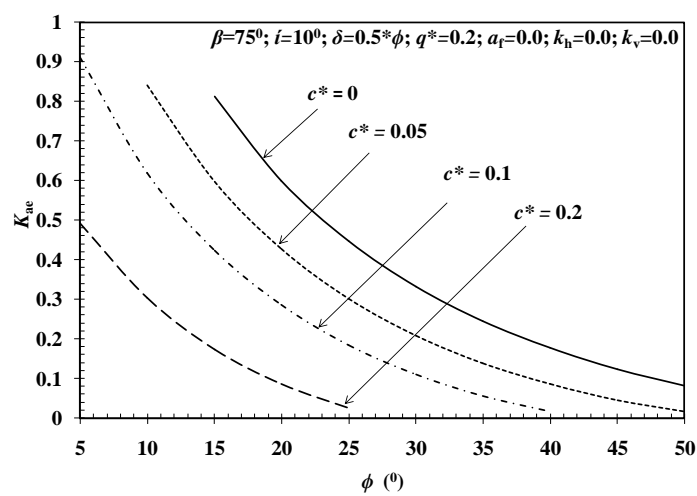

(a)

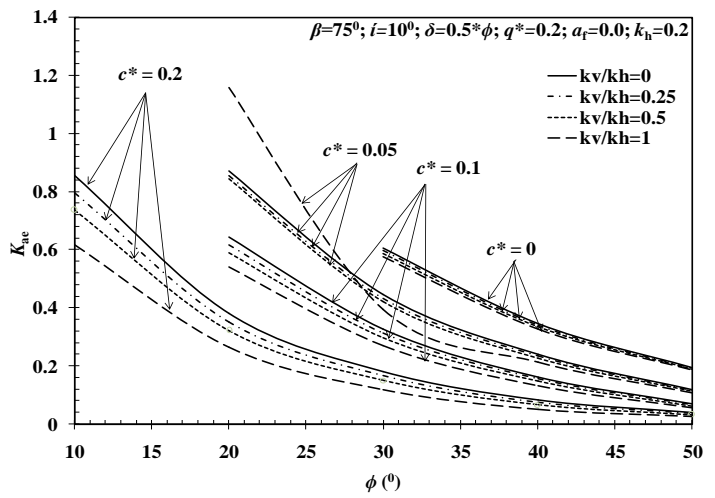

(c)

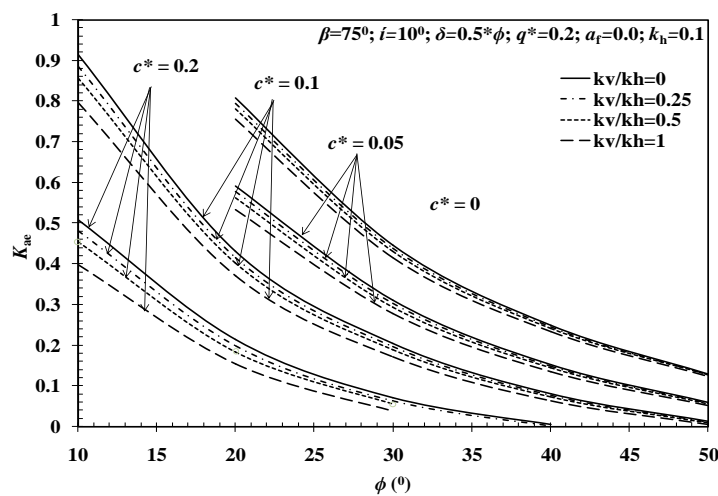

(b)

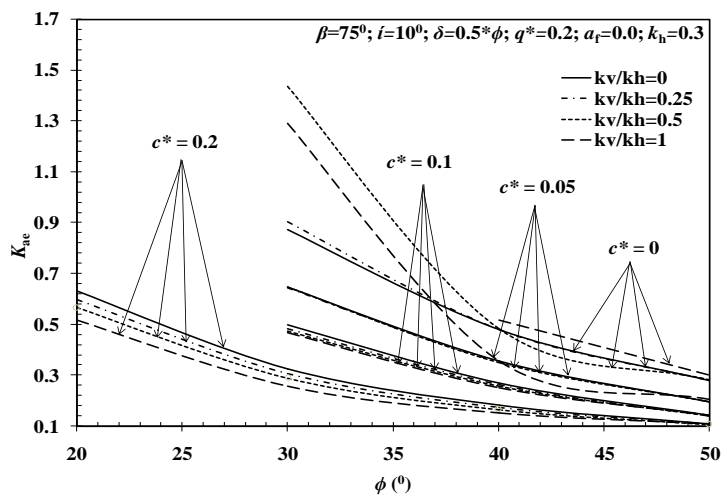

(d)

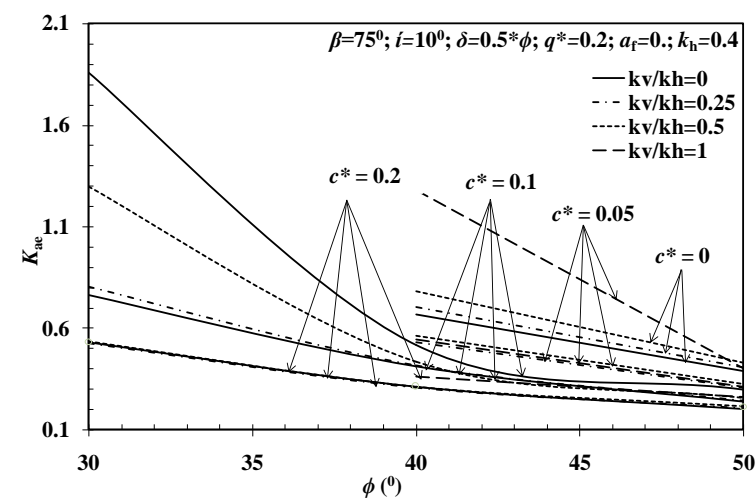

(e)

Figure 4. Design charts for $K_{\mathrm{ae}}$ for backfill slope $i=10^{\circ}$ and wall inclination $\beta=75^{\circ}$

For example; at $\beta=75^{\circ}, \phi=30^{\circ}, c^{*}=0.1, q^{*}=0.2$ and $i=10^{\circ}$ the value of $K_{\text {ae }}$ increase by about $85.6,197.1,350.4$ and $386.3 \%$, when $k_{\mathrm{h}}$ value rises from 0.0 to $0.1,0.2,0.3$ and 0.4 respectively. The percentage increase in the $K_{\mathrm{ae}}$ is about 85.6, 60.1, 51.6 and 53.5\% when $k_{\mathrm{h}}$ value increases from 0.0 to $0.1,0.1-0.2,0.2-0.3$ and $0.3-0.4$ respectively. It shows that the percentage increment is reducing till $k_{\mathrm{h}}$ equal to 0.3 , and for $k_{\mathrm{h}}=0.4$ it increases. 
International Journal of Mathematical, Engineering and Management Sciences

Vol. 4, No. 2, 409-419, 2019

https://dx.doi.org/10.33889/IJMEMS.2019.4.2-033

For vertical wall as, $\beta=90^{\circ}, \phi=30^{\circ}, c^{*}=0.1, q^{*}=0.2$ and $i=10^{\circ}$ the value of $K_{\text {ae }}$ increase by about $35.8,87.6$ and $174.9 \%$ when $k_{\mathrm{h}}$ value rises from 0.0 to $0.1,0.2$ and 0.3 respectively. The percentage increase in the $K_{\mathrm{ae}}$ is about $35.8,37.1$ and $46.4 \%$ when $k_{\mathrm{h}}$ value increases from 0.0 to $0.1,0.1-0.2$ and $0.2-0.3$ respectively. It shows that the percentage increment is increasing till $k_{\mathrm{h}}$ equal to 0.3 .

Considering the wall inclination positive as $\beta=105^{\circ}, \phi=30^{\circ}, c^{*}=0.1, q^{*}=0.2$ and $i=10^{\circ}$ the value of $K_{\text {ae }}$ increase by about $25.3,59.3$ and $108.7 \%$ when $k_{\mathrm{h}}$ value rises from 0.0 to $0.1,0.2$ and 0.3 respectively. The percentage increase in the $K_{\mathrm{ae}}$ is about $25.3,27.1$ and $30.9 \%$ when $k_{\mathrm{h}}$ value increases from 0.0 to $0.1,0.1-0.2$, and $0.2-0.3$ respectively. It shows that the percentage increment is also increasing with respect to $k_{\mathrm{h}}$ and its increases gradually.

For $\phi=30^{\circ}, c^{*}=0.1$, when the inclination angle $\beta$ from $75^{\circ}$ to $90^{\circ}$ and $90^{\circ}$ to $105^{\circ}$, then the value of $K_{\text {ae }}$ increases about 154.8 to $345.7 \%$. Yet, the successive percentage increment is reducing with respect to increase of inclination angle with backfill slope $10^{\circ}$.

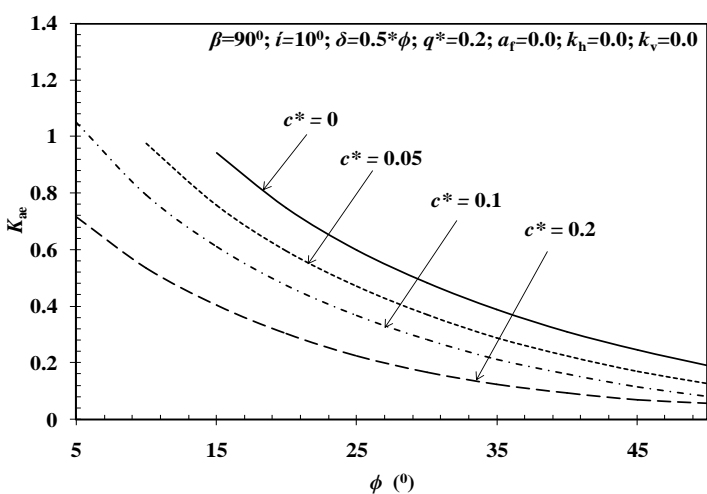

(a)

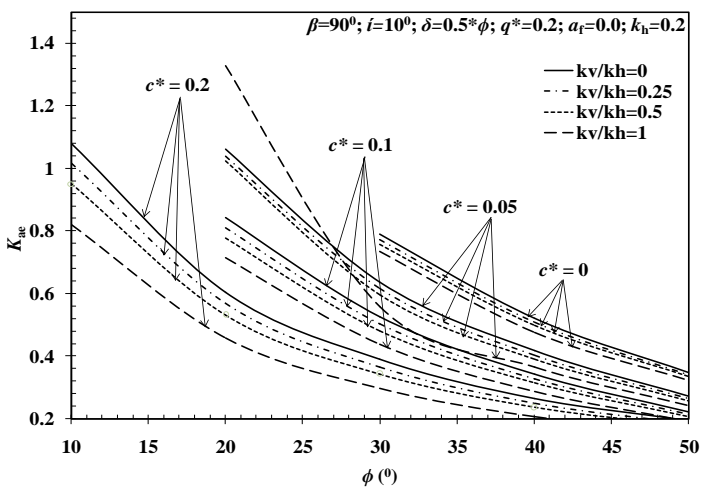

(c)

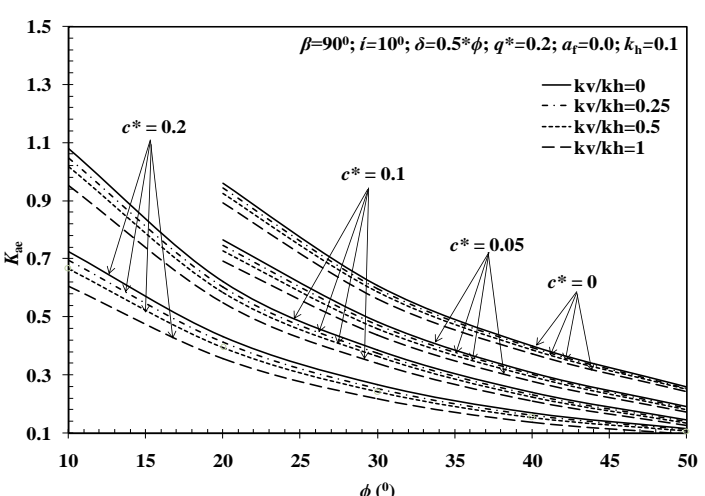

(b)

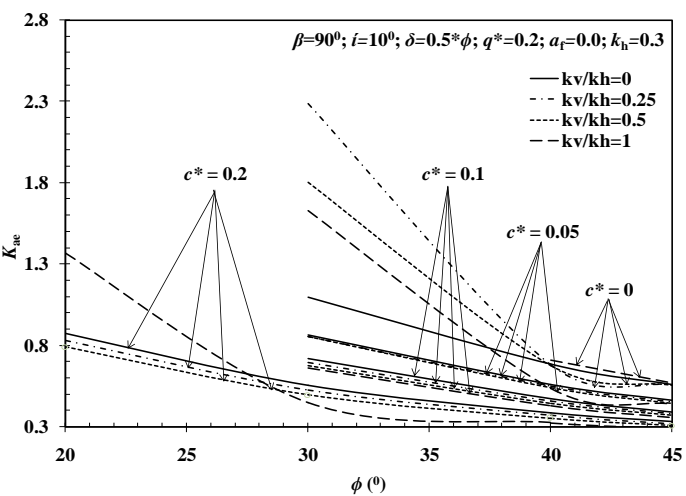

(d)

Figure 5. Design charts for $K_{\text {ae }}$ for backfill slope $i=10^{\circ}$ and wall inclination $\beta=90^{\circ}$ 
International Journal of Mathematical, Engineering and Management Sciences

Vol. 4, No. 2, 409-419, 2019

https://dx.doi.org/10.33889/IJMEMS.2019.4.2-033

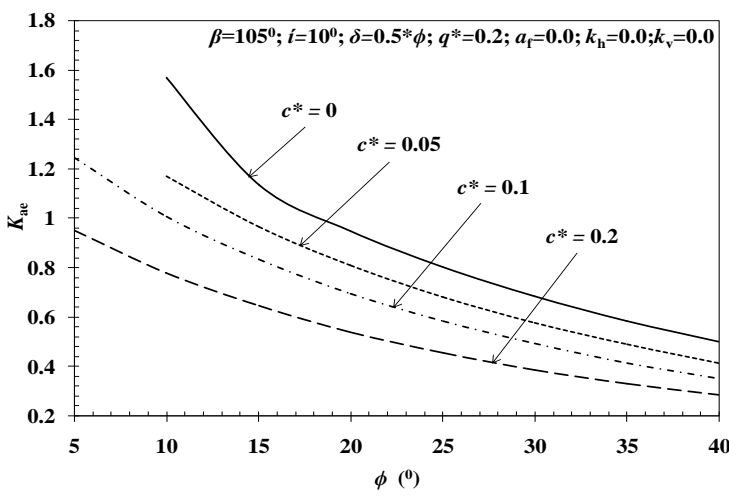

(a)

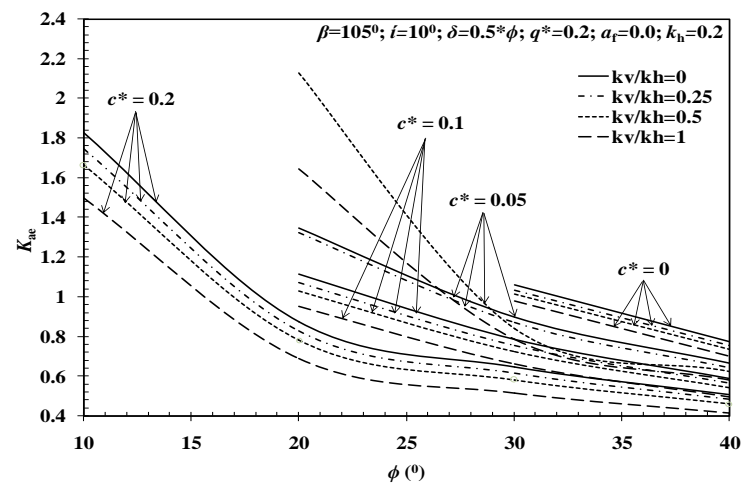

(c)

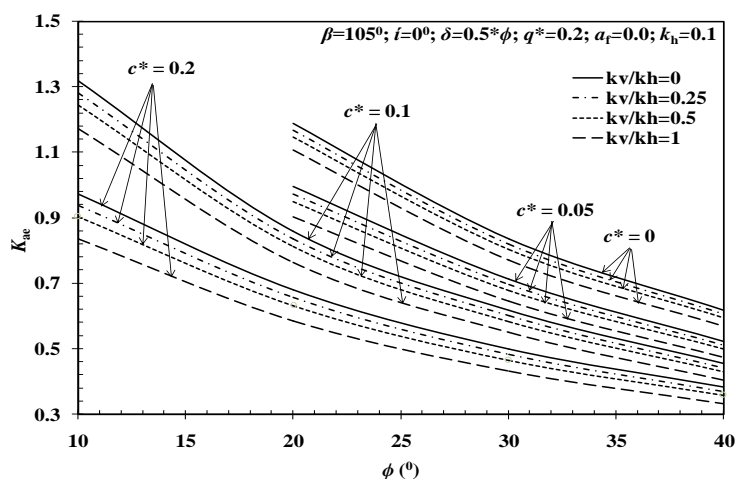

(b)

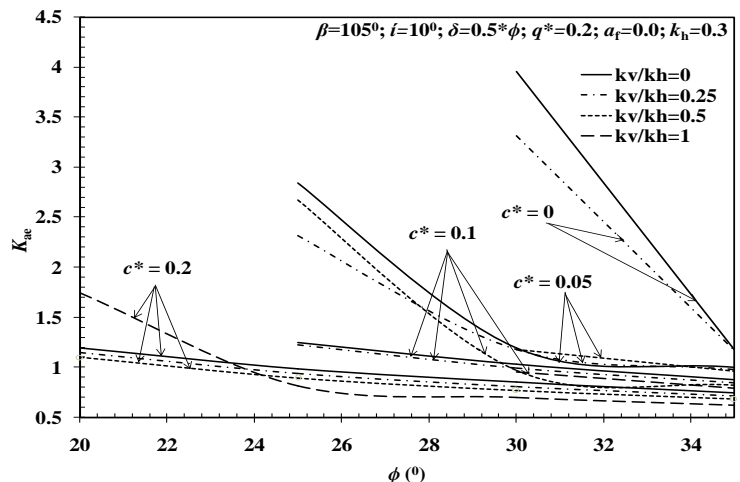

(d)

Figure 6. Design charts for $K_{\mathrm{ae}}$ for backfill slope $i=10^{\circ}$ and wall inclination $\beta=105^{\circ}$

\section{Conclusion}

According to design charts from present study, the following conclusions are summarized:

- The value of active earth pressure coefficient $\left(K_{\mathrm{ae}}\right)$ reduces with respect to increase in cohesion $(c)$ as well as angle of shearing resistance of soil backfills and disregarding of non-dimensional backfill surcharge loading in all case.

- The value of the active earth pressure coefficient $\left(K_{\text {ae }}\right)$ increases with the inclination of $\beta$ from $\left(75^{\circ}-105^{\circ}\right)$ in all case. However, the percentage increment of $K_{\mathrm{ae}}$ is marginally increases, when the backfill slope is $10^{\circ}$.

- At a given angle of backfill inclination, the value of active earth pressure coefficient $\left(K_{\mathrm{ae}}\right)$ is more for the sloping backfill case. The percentage increment of $K_{\mathrm{ae}}$, also increases for the higher value of wall inclination. 
International Journal of Mathematical, Engineering and Management Sciences

Vol. 4, No. 2, 409-419, 2019

https://dx.doi.org/10.33889/IJMEMS.2019.4.2-033

\section{Conflict of Interest}

The authors confirm that there is no conflict of interest to declare for this publication.

\section{Acknowledgement}

The authors would like to express their sincere thanks to the referee and for their valuable suggestions towards to the improvement of the paper. The authors will like to thank reviewers and editor for their constructive comments.

\section{References}

Gupta, A., Chandaluri, V. K., Sawant, V. A., \& Shukla, S. K. (2019). Development of design charts for the dynamic active thrust from $c$ - $\phi$ soil backfills. In: Adimoolam B., Banerjee S. (eds), In Soil Dynamics and Earthquake Geotechnical Engineering. Lecture Notes in Civil Engineering, 15, 111-122. Springer, Singapore

Kim, W. C., Park, D. \& Kim, B. (2010). Development of a generalised formula for dynamic active earth thrust. Geotechnique, 60(9), 723-727.

Kramer, S. L. (1996). Geotechnical earthquake engineering. Prentice-Hall, Englewood Cliffs.

Mononobe, N. \& Matsuo, H. (1929). On the determination of earth pressure during earthquake. In the Proceedings of the World Engineering, Tokyo, Japan, (pp. 177-185).

Okabe, S. (1924). General theory on earth pressure and seismic stability of retaining wall dam. Journal of Japan Society of Civil Engineers, 10(6), 1277-1323.

Shukla, S. K. \& Bathurst, R. J. (2012). An analytical expression for the dynamic active thrust from $c-\phi$ soil backfill on retaining walls with wall friction and adhesion. Geomechanics and Engineering, 4(3), 209218.

Shukla, S. K. (2013). Seismic active earth pressure from sloping $c-\phi$ soil backfills. Indian Geotechnical Journal, 43(3), 274-279.

Shukla, S. K. (2015). Generalized analytical expression for dynamic active thrust from $c$ - $\phi$ soil backfills. International Journal of Geotechnical Engineering, 9(4), 416-421.

Shukla, S. K., Gupta. S. K. \& Sivakugan, N. (2009). Active earth pressure on retaining wall for $c$ - $\phi$ soil backfill under seismic loading condition. Journal of Geotechnical and Geoenvironmental Engineering, $135(5), 690-696$. 